\title{
Analiza parametara kakvoće junećih polovica s obzirom na pasminu i spol
}

Fabijanec', T., D. Marenčić2, T. Jelen², L. Kozačinskỉi, Ž. Cvrtila ${ }^{3}$

Originalni znanstveni rad

\begin{abstract}
SAŽETAK
Cilj ovog istraživanja bio je utvrditi razinu utjecaja pasmine i spola, kao i njihovu interakciju na klaonička svojstva junećih polovica. Istraživanje je provedeno na 80 junadi od kojih je 40 bilo simentalske pasmine (20 muškog i 20 ženskog spola), a 40 (20 muškog i 20 ženskog spola) su bili križanci mesnih pasmina charolais, limousin i belgijskog plavog goveda. Spol je imao značajan utjecaj na klaonička svojstva $(P<0,001)$. Muška junad je imala značajno povoljnije vrijednosti parametara klaoničke mase i neto prirasta $(P<0,001)$. Pasmina je također imala značajan utjecaj na klaoničke parametre $(P<0,001)$. Značajno bolje vrijednosti parametara klaoničke mase, neto prirasta i randmana su utvrđene u skupini križane junadi $(P<0,001)$. Iz navedenoga se može zaključiti kako je križana junad imala značajno bolju kakvoću junećih polovica $(P<0,001)$.
\end{abstract}

Ključne riječi: kakvoća junećih polovica, spol, pasmina

\section{UVOD}

Danas tržište postavlja sve veće zahtjeve u pogledu kakvoće junećih polovica i mesa. Stoga se na liniji klanja juneće polovice razvrstavaju u kategorije i klase (EUROP klasifikacija) i ocjenjuju prema stupnju pokrivenosti masnog tkiva. U svrhu ocjene uspješnosti tova pored navedenih podataka mesne industrije još procjenjuju živu masu, klaoničku masu toplih i hladnih polovica, te na temelju istoga izračunavaju randman topli, hladni), kalo i neto priraste. Svi su navedeni podaci vrlo bitni za proizvođače, tj. tovljače, jer osim uspješnosti tova na temelju navedenih parametara se formira i proizvodna cijena.

Kakvoća junećih polovica određena je i različitim endogenim (pasmina, spol, dob klanja) i egzogenim (tehnologija tova, transport, klanje, uvjeti čuvanja mesa nakon klanja) čimbenicima (Klont i sur., 1998; Renand i sur., 2001; Čubić i sur. 2011; Marenčić i sur., 2012). Jedan od bitnijih čimbenika o kojem će ovisi kakvoća po- lovica su pasmina i spol. Genetska osnova predstavlja primarni kriterij prilikom postavljanja proizvodnih ciljeva. O genetskom potencijalu ovisiti će nakupljanje mišićnog i masnog tkiva (potkožne i intramuskularne masnoće) u tijelu junadi. Ustaljeno je mišljenje da tovna križana junad zbog heterozis učinka, postiže bolje tovne rezultate kao i bolja klaonička svojstva polovica od junadi čistih pasmina. Spol također može imati vrlo bitan utjecaj na uspješnost tova, kao i na kakvoću junećih polovica. Smatra se da ženska junad obično ima od 1,5-2 \% niže randmane, te da odlaganje masti počinje ranije i intenzivnije je za razliku od muških grla (Berg i sur., 1976; Bailey, 1984; Beacom, 1984). Ženska junad ima veći stupanj pokrivenosti masnim tkivom kod nižih klaoničkih masa. Međutim, unatoč ovim navodima, treba istači kako neka istraživanja pokazuju kako se i ženska junad mesnih pasmina mogu vrlo uspješno toviti (Kauffman, 1997; Campo i sur., 2000; Aldaia i sur., 2006).

1 Tomislav Fabijanec, struč. spec. ing. agr., student, Visokoga gospodarskog učilišta u Križevcima, Milislava Demerca 1, Križevci, Hrvatska

2 Dr. sc Dejan Marenčić, prof. v. š.; Dr. sc. Tatjana Jelen, prof. v. š., Visoko gospodarsko učilište u Križevcima, Milislava Demerca 1, Križevci, Hrvatska

3 Prof.dr.sc. Lidija Kozačinski; izv.prof.dr.sc. Željka Cvrtila, Zavod za higijenu, tehnologiju i sigurnost hrane, Veterinarski fakultet Sveučilišta u Zagrebu, Heinzelova 55, Zagreb, Hrvatska 
Stoga je i cilj ovog rada bio utvrditi razinu utjecaja pasmine (genotipa) i spola, kao i njihovu interakciju na klaonička svojstva junećih polovica.

\section{MATERIJALI I METODE RADA}

Istraživanje je provedeno na 80 junadi od kojih je 40 bilo simentalske pasmine (20 muškog i 20 ženskog spola), a 40 (20 muškog i 20 ženskog spola) su bili križanci mesnih pasmina charolais, limousin i belgijskog plavog goveda. Navedena junad je potjecala sa farme Trema koja je u vlasništvu tvornice stočne hrane Čakovec d.d. Junad je bila smještena u zatvorenoj staji na rešetkastom podu u četiri boksa, a u svakom boksu bilo je 20 jedinki. Muška i ženska junad držana je u odvojenim boksovima. Junad je ušla u tov s prosječnom starošću od $5 \pm 0,13$ mjeseci i s prosječnom težinom od $250 \pm 17,37 \mathrm{ki}$ lograma, a izašla je iz tova s prosječnom starošću od $17 \pm 0,13$ mjeseci. Tov je trajao 12 mjeseci.

Hranidba tovne junadi vršila se dva puta dnevno. Obrok je bio ujednačen tijekom svih 12 mjeseci i bio je dostupan po volji. Obrok se je sastojao od 6 kg kukuruzne silaže cijele stabljike (33\% ST), 6 kg siliranog klipa kukuruza bez komušine (57\% ST) i 1 kg super koncentrata. Prosječna hranjiva vrijednost obroka iznosila je 79 MJ ME i $1000 \mathrm{~g}$ sirovih bjelančevina.
Klanje je obavljeno u ovlaštenoj klaonici Vajda d.d. u Čakovcu (HR 8). Prijevoz junadi do klaonice izvršen je prema važećoj zakonskoj regulativi (NN 116/05). Klanje je obavljeno po standardnom postupku. Junad je omamljena pneumatskim pištoljem (Schermer) s penetrirajućim klinom. Nakon omamljivanja junadi vršeno je presijecanje velikih vratnih krvnih žila (truncus brachiocephalicus), te iskrvarenje u visećem položaju. Nakon iskrvarenja izvršena je dekapitacija i obrada polovica prema standardnom postupku (NN 20/04). Nakon klanja izvršeno je vaganje polovica i ocjena konformacije polovica prema važećem EUROP sustavu od strane ovlaštenog klasifikatora (NN, 20/04; NN, 40/07).

$\mathrm{U}$ istraživanju su korišteni sljedeći podaci: klaonička masa polovica $(\mathrm{kg})$, neto prirasti $(\mathrm{kg})$, randman (\%), EUROP klasifikacija polovica i stupanj prekrivenosti masnim tkivom (1-5). Rezultati praćenja parametara kakvoće obrađeni su statističkim programom Statistica 8.0 (StatSoft, Inc 1984 - 2007) korištenjem GLM postupka. $U$ analizi izraženosti utjecaja pasmine i spola na kakvoću junećih polovica uporabljena je ANOVA multivarijantni linearni model, a značajnost razlika utvrđena je uporabom Fisher-ovog (LSD) testa.

Tablica 1. Prosječne vrijednosti klaoničkih parametara junećih polovica na ukupno istraženom uzorku is obzirom na međuodnos pasmine i spola.

Table 1. The average value of slaughtering traits of beef halves on total sample and according to interaction of breed and sex.

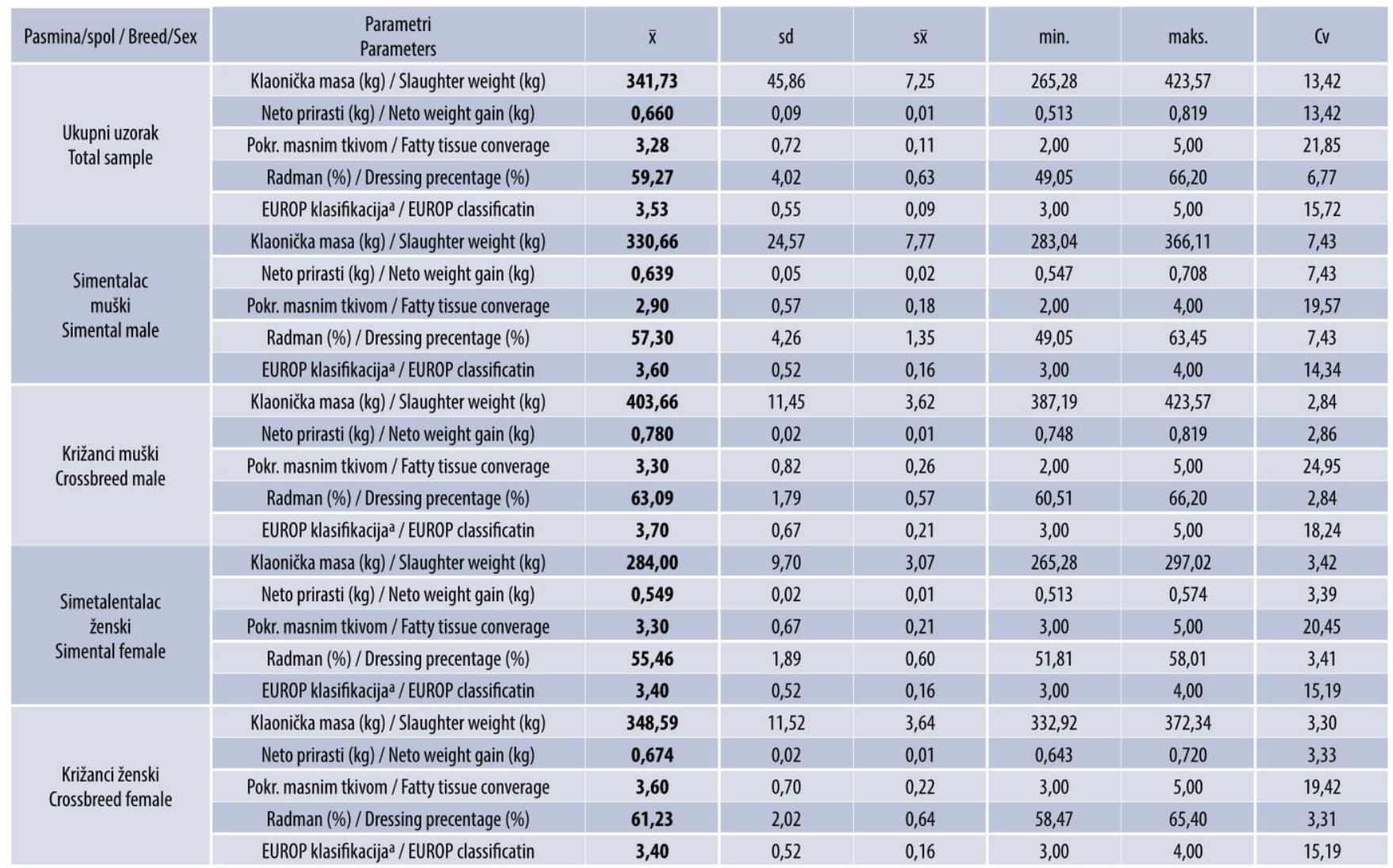

${ }^{a}$ EUROP klasifikacija: 5 (E); $4(U) ; 3(R) ; 2(0) ; 1$ (P) 
Tablica 2. Statistička značajnost klaoničkih parametara junećih polovica s obzirom na pasminu, spol i njihov međuodnos.

Table 2. The significance differences of slaughtering traits according to breed, sex and their interaction.

\begin{tabular}{|c|c|c|c|c|c|c|}
\hline \multirow{2}{*}{$\begin{array}{l}\text { Parametri } \\
\text { Parameters }\end{array}$} & \multirow{2}{*}{$\begin{array}{l}\text { Spol } \\
\text { Sex }\end{array}$} & \multicolumn{2}{|c|}{ Pasmina / Breed } & \multirow[b]{2}{*}{$s \bar{X}$} & \multirow{2}{*}{$\begin{array}{l}\text { Prosjek }^{2} \\
\text { Average }^{2}\end{array}$} & \multirow[b]{2}{*}{$s \bar{x}$} \\
\hline & & $\begin{array}{l}\text { Simentalac } \\
\text { Simental }\end{array}$ & $\begin{array}{l}\text { Križanci } \\
\text { Crossbreed }\end{array}$ & & & \\
\hline \multirow{2}{*}{$\begin{array}{l}\text { Klaonička masa }(\mathrm{kg}) \\
\text { Slaughter weight (kg) }\end{array}$} & $\begin{array}{l}0 \\
q\end{array}$ & $\begin{array}{l}330,66^{\mathrm{a}} \\
284,00^{\mathrm{b}}\end{array}$ & $\begin{array}{l}403,66^{\mathrm{c}} \\
348,59^{d}\end{array}$ & 4,90 & $\begin{array}{l}367,17^{A} \\
316,30^{B}\end{array}$ & 8,60 \\
\hline & $\begin{array}{l}\text { Prosjek' } \\
\text { Average }^{1}\end{array}$ & $307,33^{A}$ & $376,13^{B}$ & 6,76 & & \\
\hline \multirow{2}{*}{$\begin{array}{c}\text { Neto prirasti }(\mathrm{kg}) \\
\text { Neto weight gain }(\mathrm{kg})\end{array}$} & $\begin{array}{l}0 \\
\text { q }\end{array}$ & $\begin{array}{l}0,639^{\mathrm{a}} \\
0,549^{\mathrm{b}}\end{array}$ & $\begin{array}{l}0,780^{c} \\
0,674^{d}\end{array}$ & 0,01 & $\begin{array}{l}0,710^{A} \\
0,611^{B}\end{array}$ & 0,02 \\
\hline & $\begin{array}{l}\text { Prosjek }{ }^{1} \\
\text { Average }^{1}\end{array}$ & $0,594^{A}$ & $0,727^{B}$ & 0,01 & & \\
\hline \multirow{2}{*}{$\begin{array}{l}\text { Pokr. masnim tkivom } \\
\text { Fatty tissue converage }\end{array}$} & $\begin{array}{l}0 \\
0 \\
q\end{array}$ & $\begin{array}{l}2,90^{\mathrm{a}} \\
3,30 \mathrm{a}^{\mathrm{b}}\end{array}$ & $\begin{array}{l}3,30 a^{b} \\
3,60^{b}\end{array}$ & 0,22 & $\begin{array}{l}3,10 \\
3,45\end{array}$ & 0,16 \\
\hline & $\begin{array}{l}\text { Prosjek }{ }^{1} \\
\text { Average }^{1}\end{array}$ & 3,10 & 3,45 & 0,16 & & \\
\hline \multirow{2}{*}{$\begin{array}{c}\text { Radman (\%) } \\
\text { Dressing precentage (\%) }\end{array}$} & $\begin{array}{l}0 \\
0\end{array}$ & $\begin{array}{l}57,30 a \\
55,46 a\end{array}$ & $\begin{array}{l}63,09^{b} \\
61,23^{b}\end{array}$ & 0,85 & $\begin{array}{l}60,20 \\
58,34\end{array}$ & 0,88 \\
\hline & $\begin{array}{l}\text { Prosjek }{ }^{1} \\
\text { Average }^{1}\end{array}$ & $56,38^{A}$ & $62,16^{B}$ & 0,62 & & \\
\hline \multirow{2}{*}{$\begin{array}{l}\text { EUROP klasifikacijaa } \\
\text { EUROP classification }\end{array}$} & $\begin{array}{l}0 \\
0 \\
+\end{array}$ & $\begin{array}{l}3,60 \\
3,40\end{array}$ & $\begin{array}{l}3,70 \\
3,40\end{array}$ & 0,18 & $\begin{array}{l}3,65 \\
3,40\end{array}$ & 0,12 \\
\hline & $\begin{array}{l}\text { Prosjek }^{1} \\
\text { Average }^{1}\end{array}$ & 3,50 & 3,55 & 0,13 & & \\
\hline
\end{tabular}

${ }^{a}$ EUROP klasifikacija: $5(\mathrm{E}) ; 4(\mathrm{U}) ; 3(\mathrm{R}) ; 2(0) ; 1$ (P)

$a, b, c, d$ Vrijednosti u istom redu i istom stupcu tablice označene razlicitim slovima značajno se razlikuju $(P<0,001)$

Prosjek ${ }^{1}$ - prosječna vrijednost pasmina sobzirom na različiti spol; ${ }^{A} B^{B}$ vrijednosti u istom stupcu označene razlicitim slovima značajno se razlikuju $(P<0,001)$

Prosjek ${ }^{2}$ - prosječna vrijednost spola sobzirom na različitost pasmina; ${ }^{A}{ }^{B}$ vrijednosti u istom redu označene razlicitim slovima značajno se razlikuju $(P<0,001)$

\section{REZULTATI I RASPRAVA}

Vrijednosti opisne statistike klaoničkih parametra junećih polovica (klaonička masa, neto prirasti, stupanj pokrivenosti masnim tkivom, randman i EUROP klasifikacija) prikazani su u tablici 1.

Prosječne vrijednosti junećih polovica na ukupno istraženom uzorku kretale su se unutar zadovoljavajućih granica za klaoničke parametre (tablica 1). Nešto veća odstupanja od prosječne vrijednosti (sd) na ukupno istraženom uzorku utvrđena je za parametre klaoničke mase, dok je najmanje odstupanje od prosječne vrijednosti utvrđene za neto priraste. Najmanji koeficijent varijabilnosti (Cv) na ukupno istraženom uzorku utvrđen je za randman. Utvrđene prosječne vrijednosti svih istraživanih parametara veće su u skupini križane junadi.

Statistička značajnost razlika klaoničkih parametara junećih polovica s obzirom na pasminu, spol i njihovu interakciju prikazana je u tablici 2 .

Pasmina je imala značajan utjecaj na istraživane parametre junećih polovica $(P<0,001)$. Navedeno potvrđuju i prijašnja istraživanja koja navode kako genetski potencijal (pasminska svojstva) imaju značajan utjecaj na klaoničke parametre (Warriss 1990; Huff i sur. 1993; Kauffman 1997; Kreikemeier i sur. 1998; Campo i sur. 2000; Klont i sur. 2001; Page i sur. 2001; Aldaia i sur. 2006; Tatum i sur. 2007). U provedenom istraživanju statistički značajno bolje vrijednosti parametara klaoničke mase, neto prirasta i randmana su utvrđene u skupini križane junadi $\left(P<0,001\right.$; tablica 2 , prosjek $\left.{ }^{1}\right)$. Rios-Utera i sur. (2006) navode da su rast i/ili tovni prirasti uglavnom različiti između različitih pasmina, no da je tovna križana junad u većini slučajeva imala bolje parametre za težinu polovica, debljinu masti, radman, i ocjenu marmoriranosti u odnosu na čistokrvne tovne pasmine. Bailey (1984) i Beacom (1984) navode da tjelesna građa junadi ima veliku ulogu na klaoničke rezultate, osobito na radman, te da pasmine kao hereford ili simentalac imaju niži randman zbog relativno velike glave, nogu i utrobe u živoj masi koji ne ulaze u klaoničku masu trupa, za razliku od npr. pasmina angus $i$ limousine. Kako god, treba istači da većina istraživanja navodi kako su bolja klaonička svojstva kod križane tovne junadi u usporedbi s pasmina uzgojenim u čistoj krvi u većini slučajeva posljedica heterozis učinka (Klont i sur. 2001; Page i sur. 2001; Plessis i Hoffman 2007; Tatum i sur. 2007).

Spol je također imao značajan utjecaj na klonička svojstva $(P<0,001)$. Navedeno potvrđuju i prijašnja istraživanja koja navode da je spol imao značajan utjecaj na klaoničke parametre, ali i na kvalitativne odlike junećih polovica (Klont i sur. 2001; Page i sur. 2001; Plessis i Hoffman 2007; Tatum i sur. 2007). U provedenom istraživanju ženska junad je imala značajno nižu klaoničku 
masu i neto priraste $(P<0,001)$, dok su samo zanemarive razlike utvrđene između parametara stupanj pokrivenosti masnim tkivom, randman i EUROP klasifikaciju ( $P<0,05$; tablica 2, prosjek2). Tatum i sur. (2007) navode da ženska tovna junad postiže za oko 10 - 15\% niže priraste od muške junadi, te da u konačnici postiže i znatno nižu završnu tjelesnu masu. Berg i sur. (1976) navode da ženska junad ima za oko 1,5 - 2\% niže radmane od muške junadi. Kreikemeier i sur. 1998; Page i sur. 2001; Tatum i sur. 2007. navode kako je ženska tovna junad u usporedbi s muškom tovnom junadi uglavnom imala značajno niže neto priraste i kako je bila sklonija nakupljanju masnog tkiva.

U provedenom istraživanju značajno najpovoljnije vrijednosti parametara klaoničke mase i neto prirasta su utvrđene kod muške križane junadi $(P<0,001)$, dok su kod preostalih parametara (stupanj pokrivenosti masnim tkivom, randman i EUROP klasifikacija) između istraživanih skupina utvrđene zanemarive razlike $(P>0,05)$. Najlošiji rezultati klaoničkih parametara su utvrđeni kod ženske simentalske junadi. Ženska simentalska junad imala je značajno najniže vrijednosti za klaoničku masu i neto priraste $(\mathrm{P}<0,001)$, dok su samo zanemarive razlike između istraživanih skupina utvrđene za parametre pokrivenosti masnim tkivom, randman i EUROP klasifikaciju $(P>0,05)$. Zanimljiva činjenica je da su u istraživanju značajno povoljnije vrijednosti za klaoničku masu, neto priraste i randman utvrđene kod ženske križane junadi u odnosu na mušku simentalsku junad. Iz navedenog se može zaključiti kako se i ženska junad može vrlo uspješno toviti zahvaljujući heterozis učinku koji ima vrlo bitnu ulogu u poboljšanju klaoničkih svojstava polovica. Navedeno potvrđuje i nekolicina prijašnjih istraživanja koja osim poboljšanja klaoničkih svojstva ističu i poboljšanje kvalitativnih odlika junećeg mesa (Kauffman 1997; Campo i sur. 2000; Aldaia i sur. 2006).

\section{ZAKLJUČAK}

Na temelju istraživanja analize parametara kakvoće junećih polovica s obzirom na pasminu i spol može se zaključiti kako su i pasmina i spol imali značajan utjecaj na istraživane parametre kakvoće junećih polovica $(P<0,001)$. Značajno najpovoljniji rezultati parametara klaoničke mase i neto prirasta su utvrđeni kod muške križane junadi $(P<0,001)$, dok su kod preostalih parametara (stupanj pokrivenosti masnim tkivom, randman i EUROP klasifikacija) između istraživanih skupina utvrđene zanemarive razlike $(P>0,05)$. Ženska simentalska junad imala je značajno najniže vrijednosti za klaoničku masu i neto priraste $(P<0,001)$, dok su samo zanemarive razlike između istraživanih skupina utvrđene za parametre pokrivenosti masnim tkivom, randman i EUROP klasifikaciju $(P>0,05)$. Ženska križana junad je u odnosu na mušku simentalsku junad ostvarila značajno povoljnije rezultate za klaoničku masu i neto prirast $(P<0,001)$, dok su između preostalih istraživanih parametara utvrđene zanemarive razlike $(P>0,05)$.

\section{LITERATURA}

Aldaia, N., B. E. Murray, A. Martinez, M. Olivan, D. J. Troy, K. Osoro (2006): The influence of breed and mh-genotype on carcass conformation, meat physico-chemical characteristics, and fatty acid profile of musclefrom yearling bulls, Meat Science 72: 486-495.

Anonimno (2004) NN 20/04: Pravilnik o kakvoć goveđ̛h trupova i polovica na liniji klanja.

Anonimno (2005) NN 116/05: Pravilnik o uvjetima i načinu prijevoza životinja.

Anonimno (2007) NN 40/07: Pravilnik o kakvoć goveđih trupova i polovicama na liniji klanja.

Bailey, C. B. M. (1984): Gut fill affects liveweight gains. Weekly Letter \#2606, Lethbridge Research Station, Agriculture Canada.

Beacom, S.E. (1984): A comparison of four system for finishing beef heifers, Research Report, Melfort Research Station, Agriculture Canada, 63-71.

Berg, R.T., R. M. Butterfield (1976): New concepts of cattle growth, Sydney University Press, Press Bldg, University of Sydney, Australia.

Campo, M. M., P. Santolaria, C. Saňudo, J. Lepetit, J. L. Olleta, B. Panea, P. Alberti (2000): Assessment of breed type and ageing time effects on beef meat quality using two different texture devices. Meat Science 55: 371-378.

Čubić, E., M. Konjačćć, N. Kelava, A. Ivanković, T. Jakopović (2011): Boja mesa različito drzane simentalskejunadi. Proceedings. 46th Croatian and 6th International Symposium on Agriculture, Opatija 833-836.

Huff E. S., F.C. Parrish (1993): Bovine longissimus dorsi muscle tenderness as affected by post mortem ageing time, animal age and sex. Journal of Food Science 58: 718.

Kauffman, R. G. (1997): Livestock and Meat Distribution Class. U: National pork quality project, Des Moines, lowa 119-184.

Klont R. E., L. Brocks, G. Eikelenboom (1998): Muscle fibre type and meat quality. Meat Science 49,219-229.

Klont R.E., L. Brocks, G. Eikelenboom (2001): Muscle fibre type and meat quality. Meat Sci. 49:219-229.

Kreikemeier K. K., J. A. Unruh, T. P. Eck (1998): Factors affecting the occurrence of darkcutting beef and selected carcass traits in finished beef cattle. Joumal of Animal Science 76: 388-395.

Marenčć D., A. Ivanković, V. Pintić, N. Kelava, T. Jakopović (2012) Effect of the transport duration time and season on some physicochemical properties of beef meat. Archiv für Tierzucht. 55 : (2) 123-131.

Page J. K., D. M. Wulf, T. R. Schwotzer (2001): A survey of beef muscle color and pH. Journal of Animal Science 79: 678-687.

Plessis I., L.C. Hofman (2007): Effect ofslaughter age and breed on carcass traits and meat quality ofbeefsteers finished on natural pasture in the arid subtropiss of South Africa. South Africa. Journal of Animal Science 37 (3): 143-153.

Renand G., B. Picard, C. Touraille, P. Berge, J. Lepetite (2001): Relationships between muscle characteristics and meat quality traits of young Charolais bulls. Meat Sci59, 49-60.

Ríos-Utrera, A., L.V. Cundiff, K. E. Gregory, R. M. Koch, M. E. Dikeman, M. Koohmaraie, Van Vleck D. L. (2006): Effects of age, weight, and fat slaughter end points on estimates of breed and retained heterosis effects for carcass traits. Journal of Animal Science 84:63-87.

Tatum, J. D., S. L. Gruber, B. A. Schneider (2007): Pre-Harvest factors affecting beef tenderness in heifers. Executive summery, Deparment of Animal Science, Colorado state University.

Warriss, P. D. (1990): The handling of cattle pre-slaughter and its effects on carcass and meat quality. Applied Animal Behaviour Science 28: 171-186.

Dostavljeno:3.2.2017. 


\title{
Effect of breed and sex on analysed quality parameters of beef carcasses
}

\section{SUMMARY}

The aim of this study was to determine level of the influence of breed and sex, as well as their interaction on slaughtering traits of beef halves. The study was conducted on 80 beef cattle of which 40 were Simmental ( 20 male and 20 female) and 40 beef cattle ( 20 male and 20 female) were meat crossbreeds ofCharolais, Limousin, Blonde d'Aquitaine cattle. Sex had a significant effect on slaughtering traits $(P<0,001)$. Male of beef cattle had a significantly more favorable parameter values of weight slaughtering halves and netto daily weight gain $(P<0,001)$. The breed had also a significant impact on slaughtering parameters $(P<0,001)$. Significantly better parameter values of weight slaughtering halves, netto daily weight gain and dressing percentage were found in a group of crossbred beef cattle $(P<0,001)$. Therefore, from the obtained results it can be concluded that the crossbreed cattle had a significantly better quality of beef halves $(P<0,001)$.

Key words: quality of beef halves, sex, breed

\section{Auswertung der Qualitätsparameter von Jungrinderhälften in Bezug auf Geschlecht und Rasse}

\section{ZUSAMMENFASSUNG}

Ziel dieser Untersuchung war es, den Einfluss von Rasse und Geschlecht sowie deren Interaktion auf die Schlachteigenschaften der Jungrinderhälften festzulegen. Die Untersuchung wurde an 80 Jungrindern durchgeführt; davon 40 Rinder der Rasse Simmental (20 männlichen und 20 weiblichen Geschlechts), und 40 Rinder (20 männlichen und 20 weiblichen Geschlechts) als Kreuzungen der Zuchtrassen Charolais, Limousin und Weißblauer Belgier. Das Geschlecht hatte einen bedeutenden Einfluss auf die Schlachteigenschaften $(P<0,001)$. So konnten bei den männlichen Rindern bedeutend bessere Parameter der Schlachtmasse und der Nettogewichtszunahme $(P<0,001)$ festgestellt werden. Auch die Rasse hatte einen wichtigen Einfluss auf die Schlachtparameter $(P<0,001)$. Erheblich bessere Parameter der Schlachtmasse, der Nettogewichtszunahme und des Ertrags wurden in der Gruppe der Rinderkreuzungen beobachtet $(P<0,001)$. Dementsprechend war die Qualität der Jungrinderhälften bei Rinderkreuzungen bedeutend besser $(P<0,001)$.

Schlüsselwörter: Qualität der Jungrinderhälften, Geschlecht, Rasse

\section{El análisis de los parámetros de calidad de las medias canales de novillos en vista de la raza y del género}

\section{RESUMEN}

El objetivo de este trabajo fue determinar el nivel de la influencia de la raza y del género y su interacción con las características de la canal de las medias canales de novillos. La investigación fue hecha en 80 novillos de los cuales 40 fueron de la raza simmental (20 machos y 20 hembras) y 40 fueron cruce de razas charolesa, limousin y azul belga (20 machos y 20 hembras). El género tuvo una importancia significante sobre las características de la canal $(P<0,001)$. Los novillos machos tuvieron los valores de los parámetros de la masa en el matadero y del neto del crecimiento significativamente favorables $(P<0,001)$. La raza también tuvo una influencia significante sobre los parámetros de la canal $(P<0,001)$. En el grupo de la cruce de razas de novillos fueron determinados valores significativamente mejores $(P<0,001)$ de los parámetros de la canal, del neto de crecimiento y de la productividad. De lo antedicho se puede deducir que los novillos de cruce de razas tuvieron las medias canales de la calidad sgnificativamente mejor $(P<0,001)$.

Palabras claves: la calidad de las medias canales de novillos, género, raza

\section{Analisi dell'incidenza della razza e del sesso sui parametri qualitativi delle mezzene bovine}

\begin{abstract}
SUNTO
Questa ricerca aveva come obiettivo l'accertamento del livello d'incidenza della razza e dell'età, come anche la loro interazione, sulle proprietà di macellazione delle mezzene di bovino. La ricerca è stata eseguita su 80 manzi di cui 40 di razza Simmental (20 maschi e 20 femmine) e 40 (20 maschie 20 femmine) frutto dell'incrocio delle razze Charolais, Limousin e Belga blu. Sè dimostrato che il sesso incide in misura rilevante sulle proprietà di macellazione $(P<0,001)$. I manzi maschi hanno fatto registrare valori sensibilmente migliori riguardo ai parametri di macellazione come la massa e la crescita netta $(P<0,001)$. È stato dimostrato che anche la razza incide in misura significativa sulle proprietà di macellazione $(P<0,001)$. Nel gruppo dei capi incrociati sono stati registrati valori sensibilmente migliori $(P<0,001)$ riguardo ai parametri di macellazione (massa, crescita netta e rendimento). Da quanto detto può concludersi che i bovini frutto dellincrocio di più razze hanno parametriqualitativi migliori rispetto alle altre mezzene bovine $(P<0,001)$.
\end{abstract}

Parole chiave: qualità delle mezzene bovine, sesso, razza 